\title{
A COMPARATIVE STUDY OF CERVIX CYTOLOGY SMEARS WITH HISTOPATHOLOGICAL FINDINGS
}

\author{
Dhamayanthi Suryamoorthy1, Kavitha Duraisamy², Revathi Ramakrishnan ${ }^{3}$ \\ ${ }_{1}^{1}$ Associate Professor, Department of Pathology, Government Theni Medical College, Theni. \\ ${ }^{2}$ Associate Professor, Department of Pathology, Government Theni Medical College, Theni. \\ ${ }^{3}$ Associate Professor, Department of Pathology, Government Theni Medical College, Theni.
}

\section{ABSTRACT}

\section{BACKGROUND}

Cervical cancer is the one of the most common cancer in the females. There is wide variation in the incidence of cervical cancer across the world. A decrease in the incidence and mortality of cervical cancer can be achieved with effective cervical cytology screening programme. The accuracy of the cervical cytology reporting, using The Bethesda system (TBS 2001) was determined by correlating the cervical cytology findings with the histopathological diagnosis, which is the gold standard one.

\section{MATERIALS AND METHODS}

This comparative study was carried out in our pathology department for three years between 1.1.2013 to 30.12.2015. All the Pap smears sent from the gynaecology department and from the health centres in Theni district were received in our pathology department. Our pathologists followed the Bethesda system 2001 for reporting the Pap smears. Those cases with abnormal findings such as atypical squamous cells and atypical glandular cells were included in this study. In the followup study, either cervix biopsy or the hysterectomy specimens with above said diagnosis were received in our department for histopathological examination. The Pap smear reports were correlated with the histopathological diagnosis.

\section{RESULTS}

Total number of Pap smears received in our department from the department of gynaecology was 3438 . Among these, 2834 number of cases were excluded. The remaining 604 cases, 131 cases were LSIL, 286 cases were diagnosed as HSIL, 166 cases were squamous cell carcinoma. 9 cases were reported as ASCUS, 5 cases as AGUS and 7 cases were diagnosed as adenocarcinoma. Majority cases of Pap smears are in the 41-50 years of age group. The number of Pap smears received show increased incidence in the para 2 individuals. In our study, the highest incidence of Pap smear report was LSIL and it occurred in $<30$ years of age group. HSIL and SCC were observed in $>40$ years of age group. $100 \%$ accuracy in cytology reporting and histopathology correlation was achieved.

\section{CONCLUSION}

Cervix cytology screening programme is the best method of early detection and prevention of cervical cancer for a mass population. Pap smear interpretation by TBS 2001 gives better communication and understanding to the gynaecologist. The accuracy of the cervical cytology reports according to The Bethesda system 2001 can be evaluated by the histopathological diagnosis which is the gold standard one.

\section{KEYWORDS}

Cervical Cytology, Pap Smears, Histopathology.

HOW TO CITE THIS ARTICLE: Suryamoorthy D, Duraisamy K, Ramakrishnan R. A comparative study of cervix cytology smears with histopathological findings. J. Evolution Med. Dent. Sci. 2017;6(12):927-930, DOI: 10.14260/Jemds/2017/198

\section{BACKGROUND}

Cervical cancer is the second most common cancer in the females. There is wide variation in the incidence of cervical cancer across the world.1,2 A decrease in the incidence and mortality of cervical cancer can be achieved with effective cervical cytology screening programme. The purpose of the Papanicolaou smear test is to detect the precancerous cervix lesions before they become invasive cancer. The frequency of the Pap smear test for which the females undergo depends upon age, poor socioeconomic status and the previous Pap smear findings.

Financial or Other, Competing Interest: None.

Submission 08-12-2016, Peer Review 25-01-2017,

Acceptance 31-01-2017, Published 09-02-2017.

Corresponding Author:

Dr. Dhamayanthi Suryamoorthy,

\# 22/2, Srinivasa Street,

Krishnapuram Colony, Madurai-625014.

E-mail: revathiram67@gmail.com

DOI: $10.14260 /$ jemds $/ 2017 / 198$

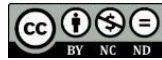

The accuracy of the cervical cytology reporting by the Bethesda system (TBS 2001) were determined by correlating the cervical cytology findings with the histopathological diagnosis which is the gold standard one. In our study, we can evaluate the accuracy of the cervical cytology report using the Bethesda system by correlating them with the histopathological diagnosis.

\section{MATERIALS AND METHODS}

This comparative study was carried out in our pathology department for three years between 1.1.2013 to 30.12.2015. All the Pap smears sent from the gynaecology department in the Theni Medical College and from the health centres in and around Theni district were received in our pathology department and stained with routine Papanicolaou stain and also H\&E staining. Our pathologists follow the Bethesda system 2001 for reporting the Pap smears.

Pap smears received with abnormal findings such as atypical squamous cells and atypical glandular cells were included in this study, and cases with cytology reports of 
unsatisfactory, reactive, metaplastic and inflammatory were excluded. The average duration between performing the Pap smears and the biopsy was one month.

In the followup study, either cervical biopsy (with or without colposcopy guided) or the hysterectomy specimens with above said diagnosis were received in our department for histopathological examination.

The specimens were fixed in formalin, processed routinely and stained with $\mathrm{H} \& \mathrm{E}$ staining for microscopic examination. The Pap smear reports were correlated with the histopathological diagnosis.

\section{OBSERVATION AND RESULTS}

Total number of Pap smears received in our department from the department of gynaecology was 3438. The most important quality assurance measure was the specimen adequacy in TBS 2001. According to the changes made in adequacy categories by TBS2001, among the 3438 cases, 2834 cases with the diagnosis of unsatisfactory, inflammatory, reactive, and metaplastic were excluded.

In the remaining 604 cases, 286 cases were diagnosed as LSIL, 131 cases were diagnosed as HSIL, 166 cases were diagnosed as squamous cell carcinoma. 9 cases were reported as ASCUS, 5 cases as AGUS and 7 cases were diagnosed as adenocarcinoma.

According to table 1, the percentage of cervical cytology cases received in our department between JAN 2013 to DEC 2013 were 985 cases (28.65\%), JAN 2014 to DEC 2014 were 1110 cases (i.e.) $32.27 \%$ and in JAN 2015 to DEC 2015, it was 1343 cases (i.e.) $39.06 \%$.

Age incidence is shown in table 2. According to table 2, there was increased incidence in 41-50 years of age group, next frequency was in 51 to 60 years of age group. The number of Pap smears received showed increased incidence in the individuals having para 2 which is shown in table 3.

Pap smears were reported by the pathologist based on the Bethesda system 2001 (TBS2001) reporting format. According to TBS 2001, the Pap smears were categorised such as LSIL, HSIL, ASCUS, SCC, AGUS, Adenocarcinoma and their incidence was as shown in table 4.

In the followup study of these cervical cytology smears as shown in table 5, all 604 cases were received either as cervical biopsy or as hysterectomy specimen. The cytological diagnosis was confirmed and correlated with the histopathological reports. The correlation is shown in table 6 .

\begin{tabular}{|c|c|c|}
\hline Year & No. of Pap Smear & Percentage \\
\hline Jan 2013 - Dec 2013 & 985 & $28.65 \%$ \\
\hline Jan 2014 - Dec 2014 & 1110 & $32.27 \%$ \\
\hline Jan 2015 - Dec 2015 & 1393 & $39.06 \%$ \\
\hline \multicolumn{2}{|c|}{ Table 1. Incidence of Cytology Cases } \\
\hline
\end{tabular}

\begin{tabular}{|c|c|c|}
\hline Age in Years & No. of Cases & Percentage \\
\hline $31-40$ & 109 & $18.05 \%$ \\
\hline $41-50$ & 210 & $34.77 \%$ \\
\hline $51-60$ & 160 & $26.49 \%$ \\
\hline $61-70$ & 101 & $16.72 \%$ \\
\hline$>70$ & 24 & $03.97 \%$ \\
\hline \multicolumn{3}{|c|}{ Table 2. Age Distribution } \\
\hline
\end{tabular}

\begin{tabular}{|c|c|c|}
\hline No. of Parity & No. of Cases & Percentage \\
\hline 1 & 204 & $50.99 \%$ \\
\hline 2 & 308 & $33.77 \%$ \\
\hline 3 & 51 & $8.60 \%$ \\
\hline 4 & 29 & $4.80 \%$ \\
\hline 5 & 8 & $1.32 \%$ \\
\hline$>5$ & 4 & $0.497 \%$ \\
\hline \multicolumn{2}{|c|}{ Table 3. Parity Distribution } \\
\hline
\end{tabular}

\begin{tabular}{|c|c|c|}
\hline Categories & No. of Cases & Percentage \\
\hline LSIL & 286 & $47.35 \%$ \\
\hline HSIL & 131 & $21.69 \%$ \\
\hline ASCUS & 9 & $1.49 \%$ \\
\hline SCC & 166 & $27.48 \%$ \\
\hline AGUS & 5 & $0.83 \%$ \\
\hline Adenocarcinoma & 7 & $1.16 \%$ \\
\hline \multicolumn{2}{|c|}{ Table 4. Cytology Diagnosis } \\
\hline
\end{tabular}

\begin{tabular}{|c|c|c|}
\hline Histopathological Diagnosis & No. of Cases & Percentage \\
\hline CIN I & 293 & $48.51 \%$ \\
\hline CIN II & 87 & $14.40 \%$ \\
\hline CIN III & 46 & $7.62 \%$ \\
\hline SCC & 166 & $27.48 \%$ \\
\hline Adenocarcinoma & 12 & 1.99 \\
\hline \multicolumn{2}{|c|}{ Table 5. Histopathology Diagnosis } \\
\hline
\end{tabular}

\begin{tabular}{|c|c|c|c|}
\hline $\begin{array}{c}\text { Cytological } \\
\text { Diagnosis }\end{array}$ & $\begin{array}{c}\text { No. } \\
\text { of } \\
\text { Cases }\end{array}$ & $\begin{array}{c}\text { No. of HPE } \\
\text { Cases in } \\
\text { follow up }\end{array}$ & $\begin{array}{c}\text { Histopatho- } \\
\text { logical } \\
\text { Diagnosis }\end{array}$ \\
\hline LSIL & 286 & $\begin{array}{c}286+7 \\
\text { (AS-CUS) } \\
=293\end{array}$ & CIN I \\
\hline HSIL & $\begin{array}{c}131 \\
(85 \text { CINII+ } \\
46 \text { CIN III) }\end{array}$ & $\begin{array}{c}85+2 \\
\text { (AS-CUS) }\end{array}$ & CIN II \\
\hline ASCUS & 9 & 46 & CIN III \\
\hline SCC & 166 & 166 & SCC \\
\hline AGUS & 5 & \multirow{2}{*nn}{$5+7=12$} & $\begin{array}{c}\text { Adeno } \\
\text { Carcinoma }\end{array}$ \\
\cline { 1 - 2 } Adeno- & 7 & &
\end{tabular}

Table 6. Cytology Correlation with Histopathology

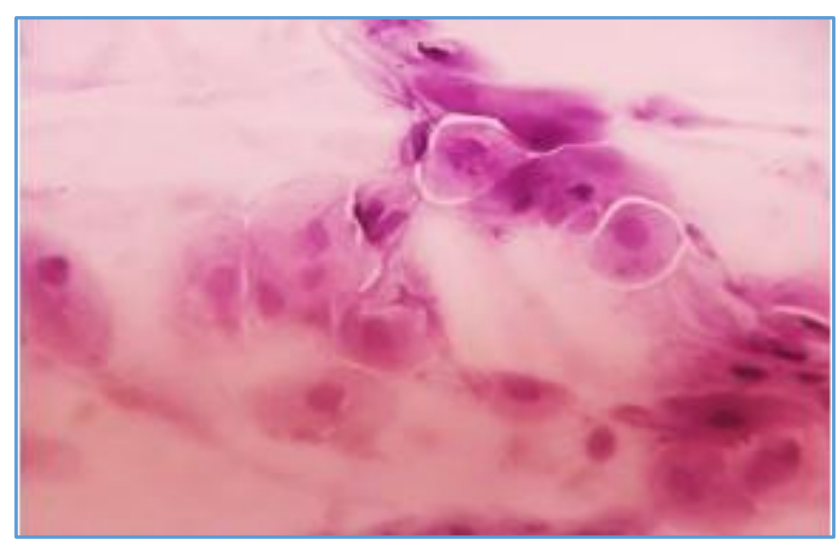

Figure 1: LSIL-Sheets of Mature Squamous cells with Nuclear Atypia 


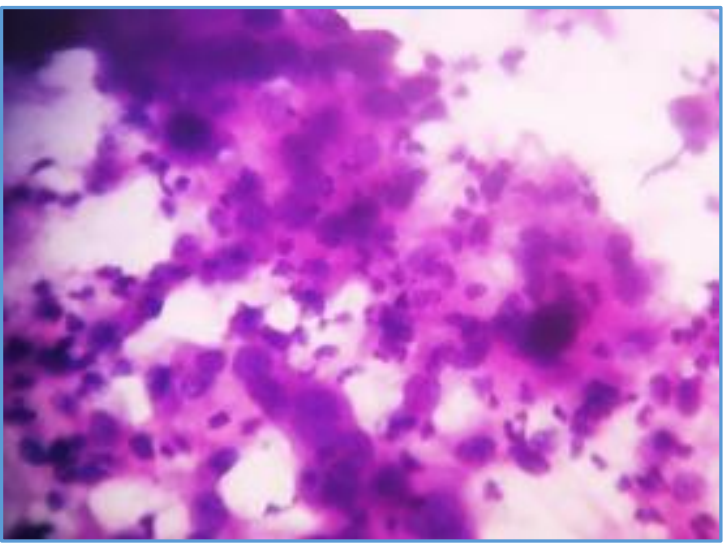

Figure 2. SCC-Sheets and Scattered Squamous Cells with Pleomorphic Hyperchromatic Nuclei

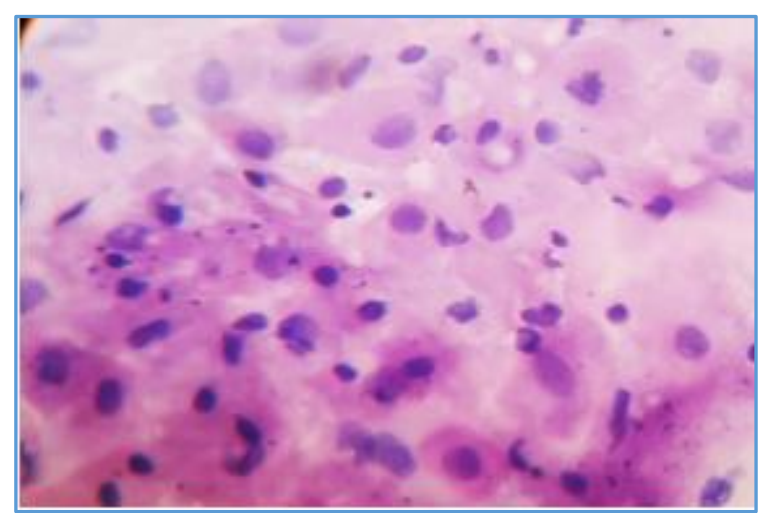

Figure 3. HSIL-Sheets of Parabasal cells with Enlarged Nucleus and Irregular Nuclear Membrane

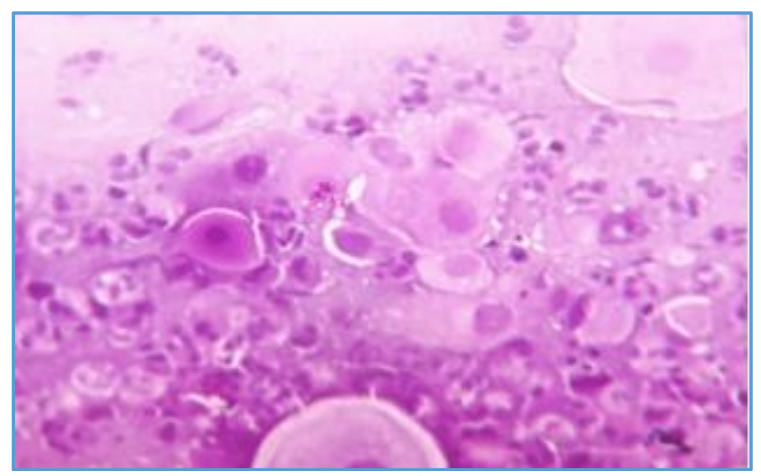

Figure 4. AS-CUS-Sheets of Atypical Squamous Cells in an Inflammatory Background

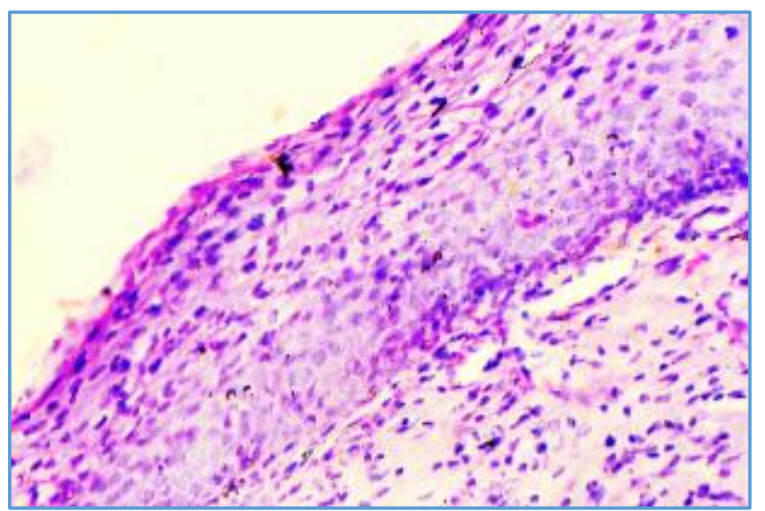

Figure 5. CIN I-Section Shows Lower One Third of Epithelial Lining with Nuclear Atypia and Pleomorphism

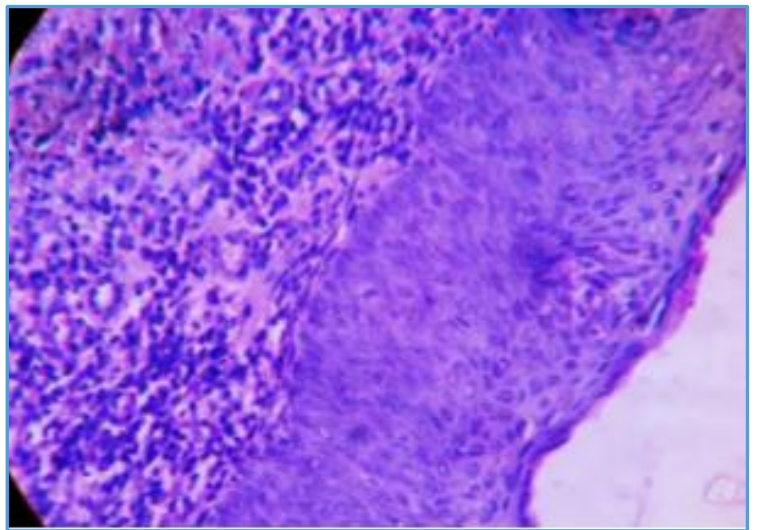

Figure 6. CIN II-Section shows lower two third of Epithelial Lining with Nuclear Atypia and Pleomorphism

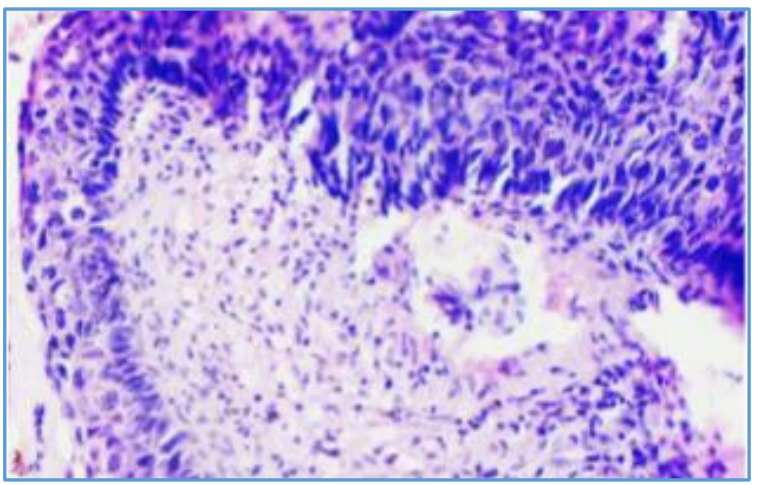

Figure 7. CIN III-Section shows Full Thickness of the Epithelial Lining with Nuclear Atypia and Pleomorphism but with intact Basement Membrane

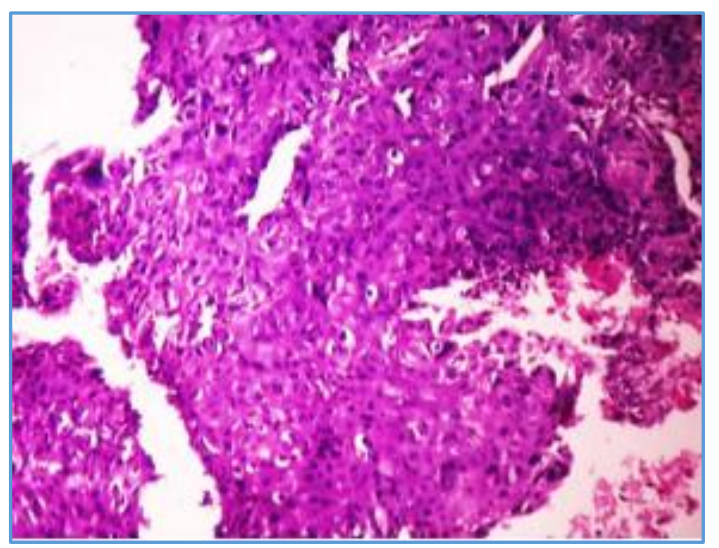

Figure 8. SCC-Sections show Sheets and Nests of Malignant Squamous Cells with Pleomorphic Hyperchromatic Nuclei

\section{DISCUSSION}

Carcinoma of the cervix is the second most common cancer in female. Cervical cancer is one major health problem in developing countries like India. The incidence and mortality of cervical cancer can be effectively reduced by cervical cytology screening programme (Pap smear). $3,4,5$

Pathologists interpret the Pap smears by TBS 2001 which gives better communication and understanding to the gynaecologist.

In India, now a days the increase in the number of Pap smear is due to the effective NCD (non-communicable disease) programme which includes the cervical cytology 
screening, thereby it paves way for early diagnosis. This leads to proper management, better prognosis, increases the life expectancy and decreases the mortality and morbidity.6,7,8 The accuracy of cytological study can be determined by the histopathological diagnosis which is most significant one..9,10

In our study, we received 3438 numbers of cervical cytology cases. Among these, only 604 cases were included in this study. Most of the patients screened were in the age group of 41 to 50 years, which totals to 210 cases $(34.77 \%)$ followed by the age group of 51 to 60 years which were 160 cases i.e. $26.49 \%$. This age distribution was similar to the study conducted by Saha. R.et al in 2005 and Gunvanti. B. Ralhod et al in 2015 which is comparable with our study.

Majority of the cases were of parity 2 which were $50.99 \%$ followed by parity 1 which were $33.77 \%$, this is similar to the study conducted by SAHA. R et al. ${ }^{11}$

According to TBS 2001, ASC (atypical squamous cells) which encompasses a spectrum of cellular changes reflecting a variety of pathological processes. According to table 4, in Pap cytology, squamous cell abnormalities were categorised as LSIL, HSIL, ASC-US, and Squamous cell carcinoma. Among these, increased number of cases occurred in the cytology diagnosis of LSIL, (Fig. 1), 286 (47.35\%) number of cases which show the features of koilocytic changes and mild dysplasia with large nuclei. This is followed by SCC, (Fig. 2) 166 cases $(27.48 \%$ ) and HSIL (Fig. 3) with the morphological features of severely dyskeratotic cells, irregular hyperchromatic nuclei, coarsely clumped chromatin which accounts about 131 cases (21.69\%).

According to Bibbo, by TBS 2001 reporting format, the cytologic changes associated with ASC-US are defined as "cytological changes suggestive of a low-grade squamous intraepithelial lesion (LSIL) that are quantitatively or qualitatively insufficient for a definitive diagnosis,"

Cases of ASC-US (Fig. 4) accounts for 9 cases, i.e. (1.49\%) with the microscopic picture of increased N/C and dyskeratosis with the background of inflammation. Atypical features are present, but definitive diagnosis was not possible due to the presence of inflammation. Hence, the diagnosis of AS-CUS was given.

The cytological diagnosis of LSIL and HSIL were seen in patients with age group $<30$ years and SCC occurred in age more than 40 yrs. This is similar to the study conducted by Amir Asotic and Suda Taric in 2014.

In the followup study, all 604 cases were available. Among these, 286 cases reported as LSIL (47.35\%) in cytology were confirmed in histopathology as CIN I (Fig. 5) and 7 out of $9(1.49 \%)$ cases reported as ASC-US show the histological features of CIN I with $48.51 \%$.

In 131 number of HSIL (21.69\%) in cytology, 85 numbers of cases show the histopathological features of CIN II, 2 cases out of 9 ASC-US cases show the features of CIN II i.e. $14.40 \%$ (Fig. 6). The remaining 46 cases in 131 HSIL (7.62\%), confirmed as CIN III (Fig. 7) in histopathology.
All 166 cases of SCC (Fig. 8) were confirmed in biopsy and managed further. 5 cases of AGC $(0.83 \%)$ and 7 cases $(1.16 \%)$ of adenocarcinoma in cytology confirmed as endocervical adenocarcinoma in histopathology. Hence, 100\% accuracy was achieved in cytology by reporting the Pap smears using TBS 2001.12

\section{CONCLUSION}

Cervical cytology screening programme is the best method of early detection and prevention of cervical cancer. Pap smear interpretation by TBS 2001 gives better communication and understanding to the gynaecologist. The accuracy of the cervical cytology reports according to The Bethesda system 2001 was evaluated by the histopathological diagnosis which is the gold standard one.

\section{REFERENCES}

[1] Papanicolaou GN. New cancer diagnosis. Proc of the 3rd race betterment conference. Battle Creek, Michigan, USA. 1928:528-34.

[2] Dehner LP. Cervicovaginal cytology, false- negative results, and standards of practice. Am J Clin Pathol 1993;99(1):45-7.

[3] The 1988 Bethesda system for reporting cervical/vaginal cytological diagnosis. National cancer institute workshop report. JAMA 1989;262(7):931-4.

[4] Crothers BA. The Bethesda system 2001: update on terminology and application. Clin Obstet Gynecol 2005;48(1):98-107.

[5] Khan MS, Raja FY, Ishfaq G, et al. Pap smear screening for pre-cancerous conditions of the cervical cancer. Pak J Med Res 2005;44(3):111-13.

[6] Sankaranarayan R, Budukh AM, Rajkumar R. Effective screening programmes for cervical cancer in low- and middle-income developing countries. Bull World Health Organ 2001;79(10):954-62.

[7] National Cancer Registry Programme. Three year report of population based cancer registries 20062008. New Delhi: ICMR 2010.

[8] Kerkar RA, Kulkarni YV. Screening for cervical cancer: an overview. J Obstet Gynecol India 2006;56:115-22.

[9] Biswas LN, Manna B, Maiti PK, et al. Sexual risk factors for cervical cancer among rural Indian women: a casecontrol study. Int J Epidemiol 1997;26(3):491-5.

[10] Missaoui N, Hmissa S, Trabelsi A, et al. Cervix cancer in Tunisia: clinical and pathological study. Asian pac J cancer prevention 2010;11(1):235-8.

[11] Ikram M, Talib W, Chatha S, et al. Carcinoma of cervix. Professional Dec Med J 2005;12(4):392-6.

[12] Saha R, Thapa M. Correlation of cervical cytology with cervical histology. Kathmandu Univ Med J 2005;3 (3):222-24. 